\title{
The Astronomical Lantern Slide Set and the Eidouranion in Australia
}

\section{Martin Bush}

School of Historical and Philosophical Studies, The University of Melbourne,

Melbourne, Australia

martin.bush@unimelb.edu.au

Martin Bush is a Research Fellow in the School of Historical and Philosophical Studies at the University of Melbourne with expertise in the cultural history of popular science and professional experience in science communication and the museum sector. Interests include planetariums, public reasoning practices and popular astronomy in Australia in the era of the lantern slide. 


\section{The Astronomical Lantern Slide Set and the Eidouranion in Australia}

Astronomical lantern slide sets were amongst the first to be commercially produced, and also the most long-lasting. The visual techniques of lanternism were shaped by earlier practice of stage astronomy, involving devices like the Eidouranion and the Dioastrodoxon. I describe the extent of this tradition in colonial Australia and argue that an examination of less central examples is revealing of its full influence.

Evidence for a number of transparent orrieries in Australia is presented, including that of John Cox in Sydney, and Phineas Moss in Tasmania. Other references to the devices of stage astronomy, such as by Laurence Hynes Halloran, are also described.

Visualisations of stage astronomy were significant in Australia as in Britain for the practice of astronomical lanternism. The transfer of visual techniques is interesting at both ends of the magic lantern period.

Keywords: magic lanterns; popular astronomy; eidouranion; history of popular science in Australia

\section{Introduction}

Astronomical lantern slides were a remarkably long-lived genre. Amongst the first images to be commercially produced as slides for magic lanterns in sets, some astronomical collections were produced and sold in nearly unchanged form from the 1830s through to the twentieth century. Over this time many of the themes of popular astronomy, too, were remarkably consistent, such as speculations about life on other worlds and the religious implications of science. These features were observed in many places: in Britain, in continental Europe, in the United States and in Australia. Lantern culture as a phenomenon showed both geographical mobilities and cultural stabilities. 
The genre of astronomical lanternism was significantly shaped by an older form of astronomical visualisation: the stage astronomy tradition, based around mechanical apparatus large enough to entertain a theatrical audience. The size of these instruments came at a cost - they were more cumbersome than the astronomical lantern slide set would prove to be- but solved different problems. They were, in any case, at least as spectacular. The Walker family's Eidouranion and Robert Evan Lloyd's Dioastrodoxon displayed illuminated glass globes, seemingly suspended in mid-air, moving around a darkened stage to simulate the motions of the solar system. At the beginning of the nineteenth century, these performances and associated transparency paintings were a familiar point of reference for audiences in many places: Britain, continental Europe, the United States and in Australia. The stage astronomy tradition of Walker, Lloyd, and their successors and imitators, also shows geographical mobilities and cultural stabilities.

A study of the influence of stage astronomy ${ }^{1}$ on lanternism reveals aspects of the mobility of technological form while highlighting the continuity of cultural associations of the practice of popular astronomy. Optical forms of demonstration that arose through stage astronomy became central to astronomical lanternism. This article examines this influence. I review the development of the astronomical lantern slide set in Britain before turning to a focus on the period of overlap between larger transparency paintings and projected lantern slides. I describe evidence for the transference of this tradition to Australia, with the construction of Eidouranion-like devices in the colonies, and their importance for early and mid-century Australian publics. A focus on colonial Australian practice forms a useful comparative to the British practices that have been densely studied and demonstrates the twin aspects of mobility and particularity of popular science. 


\section{The astronomical lantern slide set stabilised across the nineteenth century}

Astronomical lantern slide sets became increasingly stabilised as a technological form throughout the nineteenth century. Their application to public display tracked both cultural and technological developments of magic lanterns, in particular their illuminants, with small-scale displays in the early part of the nineteenth century leading to larger, public performances once the limelight had been developed and applied to projection. These innovations will be briefly reviewed below.

That progression is largely true of other kinds of content displayed with lanterns. What is remarkable about astronomical lantern slides is how they were the site of technological innovation from the very beginning, and how specific images were so consistently interpreted in a framework of broad-scale cultural sensibilities, like the sense of the astronomical sublime. Golinski (2017), in describing the prior tradition of stage astronomy, argued that the success of the Walker family's Eidouranion lay in both its technological and aesthetic aspects. I suggest that these dual aspects also overlaid and influenced early lantern culture.

\section{The astronomical lantern slide set developed from the late eighteenth to the mid nineteenth century}

Commercially produced astronomical lantern slide sets appear in Britain in the last decade of the eighteenth century. The first advertised sets with a certain date seem to be those produced by the London instrument makers William and Samuel Jones. ${ }^{2}$ William Jones started his optician business in London around 1782, in partnership with his father, John Jones, until 1791 and thereafter with his brother Samuel. In 1797 W \& S Jones advertised an item not found in their 1795 catalogue, "a new set of moveable painted sliders, shewing the fundamental principals of astronomy, with the real and apparent motions and positions of the planets, stars, \&c" (W. and S. Jones 1797, 3). 
These first movable slides were almost certainly the slipping slide animations of solar and lunar eclipses ubiquitous in later sets by both the Jones and others, as seen in Figure 1.

Figure 1: Astronomical slides by W. \& S. Jones, slipping type, circa 1830. a): Solar eclipses. 1 b) Lunar eclipses. Courtesy of The Bill Douglas Cinema Museum, University of Exeter.

By this time slipping slide techniques had already been introduced into the highly popular Phantasmagoria sound and light shows of the late eighteenth century. From the beginning, astronomical lantern slides picked up on these kinds of animated movements. Since the mid-eighteenth century, uses of the magic lantern for entertainments such as the Phantasmagoria had been considered a way to "surprise and amuse ignorant people, and for the sake of Lucre, than for any other purpose" (Martin $1740,292)$. The goal of scientifically-minded reformers was to apply the lantern "to more useful purposes" (Martin 1740, 293). By the end of the eighteenth century, Phantasmagoria practitioners like Étienne-Gaspard Robertson and Paul Philidor had developed sophisticated and highly popular shows. Copying techniques from these shows but applying them to the subject of astronomy was one means by which the Jones brothers tried to reorient lantern practice towards 'more useful purposes'.

Another set of lantern slides that has been dated by the British Library to 1797, albeit uncertainly, is a part of the "Astronomical Lucernal" advertised by Mary Dicas of Liverpool (Clegg 1797). It is likely that the British Library date for this device is about a decade too early. ${ }^{3}$ In any case, even with a later date, the nine astronomical movements of the lucernal are one of the first known uses of rackwork astronomical animations for slide projection. More complex than Jones' slipping slides, each of these nine movements was a group of concentric brass rings with inset images. Each 
movement could be inserted into a separate winch-operated mechanized slide, and thereby projected.

\section{The development of lantern illuminants had a strong effect on the genre}

Only small images could be set into rotating brass movements, so they required strong illumination for good effect. Rackwork slides, such as seen in Figure 2, would not become common until after the application of limelight to slide projection. ${ }^{4}$ Dicas' lucernal used an oil lamp. Spermaceti was suggested as it provided the brightest light for lantern projection. Nonetheless, performances using the Dicas' lucernal, like other projectors of the time, would have been "intimate, with the lanternist projecting his or her pictures from a distance of a few feet" (Heard 2005).

Figure 2: Astronomical slide, rackwork type, circa 1850. Diurnal Motion of the Earth. Courtesy of Museums Victoria.

Better lantern illuminants, improved slide manufacture and a more favourable cultural situation in Britain all led to an increase in the number of astronomical slide sets available after 1815. One major improvement was the copper plate technique of Philip Carpenter, which transformed slide manufacture. Carpenter's first astronomical set appeared in 1822. By this time use of the Argand lamp had allowed larger audiences for lantern projection (although Robertson and Philidor required darkened spaces to present their Phantasmagoria effects for theatrical crowds), and the Jones brothers had an improved astronomical set and optician Charles Blunt had also produced one. Alongside these technological developments, the social acceptability of science increased in the Post-Napoleonic period. Previous decades had seen science associated with radical politics, and looked upon with suspicion by many in Britain (Golinski 2017). A return to political stability facilitated a return to a greater social acceptability of science. 
The most dramatic technological advance for lanternism in the first half of the nineteenth century was surely the application of limelight—invented for lighthouses_to projection. This allowed public performance of lantern slides for large audiences in ordinary halls and lecture theatres. Instrument maker Edward Clarke claimed in his catalogue to be the first, in 1840 , to have used limelight for lantern projection at the Adelaide Gallery (Clarke 1842, 34)—including astronomical slides-while the Royal Polytechnic claimed credit for this innovation as well. It was only with the development of the limelight that lantern shows could truly produce complex astronomical visualisations for large audiences in ordinary theatres and halls.

\section{The astronomical lantern slide set came in a number of different forms}

The astronomical lantern slide set in the limelight era settled into two main formats. The rackwork set of nine or ten slides was almost identical between manufacturers:

Carpenter and Westley, Newton, Dollond and several others. Proofs of the sphericity of the Earth, demonstrations of the annual and diurnal motions of the Earth, simulations of solar and lunar eclipses, an explanation of the theory of tides, and a grand orrery slide showing the orbits of all known planets were common to all rackwork sets. They were used around the world into the twentieth century. That in the 1920s it was still viable to advertise a set of wood-framed lantern slides (Flatters \& Garnett 1924), as seen in

Figure 3, unchanged from the mid-nineteenth century, in a catalogue otherwise full of photographic slides, speaks to the durability of that format.

Figure 3: Advertisement for set of rackwork astronomical slides from Flatters \& Garnett lantern slide catalogue, 1924. Source: Internet Archive

The larger sets with slipping slide animations and another thirty to forty still images would also continue, albeit with slightly more variation. One of the first such variations 
was the set produced by Blunt by 1816 . Figure 4 shows an advertisement for Blunt's lantern slides. Not only is astronomy first listed, the description takes up nearly half of the space; clearly astronomy was important for marketing slides.

Figure 4: Advertisement for set of astronomical slides by Charles Blunt, from the Quarterly Review, vol. 14, (27 \& 28), 1816. Source: Internet Archive

Distinctive features of the advertisement text include the appearances of the planets "as viewed through Herschell's Telescope" and "highly magnified views of the most curious parts of the Moon's surface, to promote the enquiry into its natural construction, and the probability of it being inhabited" (Blunt 1816). Although no surviving sets are known, Blunt went on to produce the illustrated book Beauty of the Heavens. This work was explicitly described as a "Family Astronomical Lecture" (Blunt 1840, v); the literary form draws on the lecturing traditions of astronomical lanternism and stage astronomy. Although the printed form is more extensive than most spoken lectures, the contents of this work can be taken as indicative of Blunt's interests, including the features of the Moon as shown in Figure 5. (Blunt would, however, be far more circumspect about the habitability of the Moon in this work, noting only that "If the moon may be supposed to be inhabited by beings like ourselves, it is evident, from this explanation of her appearances to the earth, that the earth must also present phases" (Blunt 1840, 47).

Figure 5: Image of the lunar surface, from Charles Blunt's Beauty of the Heavens, 1840.

a) Kepler b) Cleomedes c) Fracastorius d) Tycho. Source: ETH-Bibliothek Zürich

\section{Astronomical lantern slide sets were influenced by earlier media forms, and went on to influence others}

Blunt's 1816 astronomical slide set was accompanied by a "descriptive volume", that is 
a reading that described the slides, and provided the basis for a lecture (as Beauty of the Heavens would later do). With such a pamphlet, anyone with a decent education could present these slides, regardless of whether or not they had any background knowledge of astronomy. Such slide readings would prove to be important for the spread of lantern slide sets. Reliable manufacturing processes, standardised slide formats and descriptive readings meant that these sets were very literally culture put into a box, able to be shipped anywhere around the world. The astronomical lantern slide set was a technologically stable form, but stable in a way that made it geographically mobile. They are in this way a good case of "immutable mobiles" (Latour 1990).

Early astronomical lanternism in Britain was influenced technically by Phantasmagoria shows, and in turn had an influence in publishing. However the content of astronomical lantern shows was earlier influenced by the tradition of stage astronomy. An interesting aspect of both Blunt's set and Dicas' Lucernal is that they were explicitly described as Eidouranions: Dicas's was a "Portable Eidouranion", Blunt's a "Complete Eidouranion, on a small scale". Historians of the magic lantern now commonly observe that far from appearing as an entirely new phenomenon, the screen culture drawn upon by early cinema was to a large degree developed by lanternist practice in the nineteenth century. Similarly, early nineteenth century British astronomical lanternism build on audience expectations produced by the earlier visual tradition of stage astronomy. The trajectory of new media forms is strongly influenced by such expectations and early innovators often see themselves as continuous with earlier practices. There is an analytic danger in remaining too closely attached to any particular technological form. Just as "area studies run the risk of enforcing untenable geographic parameters around the survey of otherwise mobile cultural technologies" (de Courcy 2018) in magic lantern studies, so too can a similar point be made about the 
studies of particular media forms themselves. Instead, magic lantern studies should aspire to the kind of intermediality and interdisciplinarity called for by Bigg and Vanhoutte (2017). In particular, I argue that an examination of the space between different media forms throws attention back onto audiences, practitioners and content.

\section{Stage astronomy was largely based around transparency painting}

The Eidouranion referred to by Dicas and Blunt was the first stage astronomy device and the longest lasting. Developed by Adam Walker in the 1770s, it was used by him and his two sons until the late 1830s. Figure 6 shows an illustration of Deane Franklin exhibiting the Eidouranion in 1817 at the London Opera House (later Lyceum Theatre). The Walkers were the first of many stage astronomers; collectively they developed the cultural associations of popular astronomy for British and, later, Australian audiences. The Eidouranion, the Walkers and the stage astronomy tradition in general are detailed by Golinski (2017) and Huang (2016). Stage astronomers presented spectacular visualisations to audiences in theatres and lecture halls, using large mechanical devices, and drawing on contexts both "commercial and sublime" (Huang 2015). Both of these contexts would be important for the astronomical lantern tradition that followed.

Figure 6: Deane Walker exhibiting the Eidouranion at the English Opera House in 1817. S.176-1997 () Victoria and Albert Museum, London

\section{A wide range of performers contributed to stage astronomy}

The Walker's Eidouranion was the most famous instance of stage astronomy, but was just one of many. The main rival to the Eidouranion was the Dioastrodoxon exhibited by Robert Evans Lloyd from some time around 1800 until his death in 1838 after "nearly 50 years in the unfolding of that sublime science" (Ipswich Journal 1838) as an astronomical lecturer. John Wallis, the astronomical lecturer associated with the Royal 
Institution in the 1830s, had "an extensive mechanical apparatus and large transparent scenery" (Huang 2015, 150). George Bartley, a famous actor, had a device called the Ouranologia. The number of lecturers exhibiting devices in Britain by the 1820 s and 30s was large. Scholarly attention has been justifiably oriented to exemplary performers with large influence, yet the reach of the tradition as a whole is revealed by the more numerous, less famous lecturers. Just a few examples of other British lecturers include Robert Children, Robert Goodacre, John Bird, Mr Holden, William Berry, Mr Hayes, Mr Smith, Mr Bird and James Howell. Two advertisements for such performances are shown in Figure 7. Some of these were operating until well into the 1850s. Taken as a whole, stage astronomy held public prominence for about eighty years, not much shorter than the era of astronomical lantern slide sets.

Figure 7: Broadsheets advertising performances of stage astronomy. a) Mr Rogers, 1824. Courtesy of the British Library. b) Mr Franklin, 1834. Bodleian Library, University of Oxford: John Johnson Collection; Entertainments folder 10 (29) Lectures.

\section{The apparatus combined static and mechanical transparency painting}

Opinions have varied about the construction of Eidouranion-like devices from sets of "large ring-wheels" (King and Millburn 1978) to having "incorporated phantasmagoria effects" (Bird 2005). Golinski (2017) provides a systematic discussion of these options, including reference to an article in the Magazine of Science by George William Francis (1840). Diagrams from this article are reproduced in Figure 8.

Figure 8: Diagrams from the Magazine of Science, Apr 4, 1840. a) Vertical tellurion b) Detail, side view c) Detail, illuminated globe. Source: Internet Archive.

Francis’ Magazine of Science article describes these devices as illuminated transparency paintings. The most important components, like the sphere representing the Earth, were 
internally lit glass globes. Others were flat transparency paintings, backlit. The apparatus described in the article, specifically likened to Wallis's device, does not incorporate projections of small-scale images, although clearly these were themselves a component of some later performers.

Static transparency paintings were a component of most performances. Walker's Epitome describes "auxiliary scenes" that include

maps of the Moon during its exhibition, particularly one of five foot diameter, made from telescopes of the largest magnifying power and laid down with the most minute correctness, with maps of the Earth as seen from the Moon, indicating from this similarity that they are worlds of nearly similar construction. (Walker 1798)

The Cosmorama exhibited at the Pantheon in 1807 was an extensive series of such paintings with a single animated machine. One painting was described thus.

The intention of this transparency is to shew the relation and dimensions of different celestial bodies, by the representation of their diameters ... The right side of the transparency shews likewise the Sun's diameter as it appears to the inhabitants of each separate Planet (An Explanatory Catalogue of the Cosmorama 1807)

The advertisement of Mr Rogers in Figure 7 a) draws attention to the transparency paintings executed by Mr D’Arcy as a point of pride.

Theses transparency paintings involved large — sometimes very large - paintings on a semi-transparent gauze that was backlit. It was a skilled art form: "Since the effect of the finished transparency depended upon the distinctness of the shapes and the clarity of the colouring, changes could not be made at whim, neither could mistakes be overpainted" (Callaway 2000). Despite the skill required, by the 1820 s it had come to be considered an inferior, purely decorative form of art, and particularly associated with the recreational pursuits of middle-class women (Barnaby 2009). Backlit transparent 
images, or "illuminations", were also very publicly displayed, although these were often simple motifs or words rather than fully painted scenes.

In Britain, transparency painting persisted across the nineteenth century. Although some transparent images were still being produced in the 1870s (Hawthorne $1873,96)$, and public illuminations for special events continued into the twentieth century, by the late nineteenth century the art form of transparency painting was largely over.

\section{The technological frame of stage astronomy was oriented to individuality}

The stage astronomy tradition comprised many lecturers, hundreds of transparency paintings and much apparatus. The Magazine of Science article mentions different ways of arranging the Vertical Tellurion to display different kinds of astronomical motions. Even these variations would not account for all of the effects that the lecturers produced. The illuminated globe representing a comet and its tail

descends from the top of the Machine; its train increasing in length and lustre till it arrives at the Sun diminishing as it ascends. Its orbit is so eccentric that the small part of it visible is not sensibly to be distinguished from a parabolic curve; and in this representation (Walker 1798, 25-26)

This comet effect was a feature of both the Walkers' and Lloyd's performances. It could easily be produced - but not by the machine described by the Magazine of Science. Some lecturers, like Goodacre and Wallis, specifically described the different pieces of apparatus that they used. Others, like the Walkers and Lloyd, incorporated all of their different machinery under one name. These overlapping usages of technologies and terminologies by practitioners reflect a "technological frame" (Bijker 1995) that was oriented towards the particular: of individuals generating or reproducing specific visualisations from stage to stage; mobile from theatre to theatre. This frame resisted 
stabilisation - and as a by-product resulted in the uncertainty of historians trying to unpick the technological form.

Some contemporary descriptions do assist in this unpicking. Goodacre described a series of catastrophes that occurred during one of his performances. His assistant William "had forgotten to fule the drop scenes and the Vertical Tellurian stood exposed" (Goodacre 1821). Wellbeloved in London Lions describes Walker's Eidouranion and Bartley's Uranologia as constructed through "painting and mechanics" (Wellbeloved 1826). Maria Edgeworth describes a lecturer who "should have pleasure in showing Frank the orrery again, and in letting him see the concealed machinery, by which it was moved." (Edgeworth 1825, 2:262-63) These give some indication of the technological form, and requisite skills of the practitioners, and they are consistent with the Magazine of Science's description.

\section{The cultural associations invoked by stage astronomers persisted}

The development of this 'concealed machinery' and its visual performance accompanied a transformation in the aesthetics of popular astronomy. Literature of the mid-eighteenth century, like Tom Telescope's (1761) Newtonian System of Philosophy, unsurprisingly, had an expository mode of demonstration. Although many stage astronomers shared Telescope's goal of interpreting astronomy for its religious implications, the rise of stage astronomy accompanied a shift to more visual forms of persuasion. 'Teaching through the eye' was the means through which the sublime science would reveal its lessons. There were two components to this: the universe itself was understood to have moral value, and a visual representation of this system was believed to be able to convey this value.

This religious and moral instruction was a common theme of popular astronomy, but not the only one. As the tradition of stage astronomy comprised many people, it was 
enacted with diverse motivations; stage astronomers drew from a consistent, but not monolithic palette of cultural associations. Rogers and Franklin were examples of popular astronomers with strong religious inclinations. The Walkers readily deployed religious themes, but also focussed on the 'plurality of worlds'. Golinski (2017) suggests that they navigated the heretical implications of this theme in the early nineteenth century through deployment of the astronomical sublime.

Other lecturers, like Wallis and Adams, emphasised religious content less strongly, focussing more on the demonstrations of the science. But here, too, persistent themes were present. One was the role of astronomy as the perfect science. Bartleywhose lecture engaged most of these common themes - stated

Such are the advantages which society have derived from the cultivation of this science; but there is yet another, which, though less evident to the world in general, is nevertheless inestimable in the Eyes of a Philosopher. This is the knowledge which it affords us of nature; of the true system of the World; and the invariable laws by which it is governed. (Huang 2015, 310)

A related aspect was the role of the history of science in relation to the nature of thought; astronomy was also the first science. Bartley made several references to the “philosophers of antiquity" while Lloyd (1810) subtitled his Epitome as “A concise History of its Origins and Proofs'.

All of these themes, and their visual expressions, would become a prominent part of the lantern tradition. Astronomical lantern lecturing from a natural theology perspective would persist until the end of the nineteenth century (Bush 2018) while the presentation of astronomy's exemplary character and historical consciousness would also persist. An example of the historical consciousness of astronomical lantern slide sets is the near-ubiquitous presence of slides showing the 'Systems of the World'Ptolemaic, Copernican, Tychonic and Newtonian, as seen in Figure 9. An additional 
aspect of some slide sets that touched on astronomy's history and exemplary nature is a focus of the person of Isaac Newton.

Figure 9: Astronomical slide, circa 1847. Copernican and Tychonic 'Systems of the World'. Courtesy of Museums Victoria.

\section{Astronomical lantern sets were well used in Australia}

This astronomical lanternist tradition was well practised in Australia. It drew on the British practices described above, but also developed local aspects. Most colonists of the 'land under the southern stars' understood themselves through a connection with British culture, but this connection was a mobile one. Scientific entertainments, like astronomical lantern lectures were an expression of this relationship. Such entertainments were delivered by itinerant performers, recent settlers and colonial institutions. Links to 'home' were reinforced with personal connections and trading relationships, as well as cultural associations.

As in Britain, astronomical lantern slides would be prefigured by Eidouranion-like devices in Australia. Multiple technologies of display co-existed and cross-pollinated prior to the dominance of the lantern slide set for visualisation performances in midcentury. Before detailing some of the evidence for these technologies I will give a brief overview of lanternism and astronomical slide sets in Australia.

\section{Australian lanternism broadly followed British trends}

The period of lanternism in Australia, and practices generally, followed British trends, albeit with some clear variations. ${ }^{5}$ Lanterns and small scale lantern shows start appearing in Australia in the 1820s, and by mid-century public performances were widespread. In the $1880 \mathrm{~s}$ and $90 \mathrm{~s}$, the cultural shift in attitudes to authority worked 
against the generalist lecturer "ready at a moment's notice to talk upon any topic suggested" (Bendigo Advertiser 1906), and in favour of celebrity lecturers, expert in a particular field. The 1880 tour of Australia and New Zealand by popular astronomer Richard Proctor, and his use of a carefully curated set of photographic lantern slides, was a watershed in this regard (see eg Bush 2017b). As elsewhere, lantern practice in Australia co-existed with early cinema for many years and indeed survived in specific contexts such as church and community groups, museums and universities. The significant difference between Australian and British practice lay in the institutional basis of the practitioners. With one exception, museums and commercial exhibitions did not appear in Australia until the second half of the nineteenth century and any case none were as extensive as London institutions like the Royal Institution, the Royal Polytechnic or the Adelaide Gallery. At the other end of the scale, the larger distances and smaller populations meant that itinerant lanternists were not viable until the very end of the nineteenth century. ${ }^{6}$ The bulk of lanternist practice in Australia was undertaken by practitioners from a middle layer of institutions: schools, churches and Mechanics' Institutes.

\section{Astronomical lecturing was popular in Australia}

As in Britain, astronomical lantern sets were amongst the first to appear in Australia. In 1837 Francis Low, who was also an architectural model-maker of some note, gave lantern performances using "the most powerful and perfect optical instrument, commonly called the Phantasmagoria Lantern, ever imported into this colony" (Colonial Times 1837a). The subject of his presentation was astronomy and the advertised synopsis of his talk suggests that he was using a standard astronomical lantern set. A decade later, one of the first limelight shows in Australia was given by Henry Kesterton in Adelaide and, again, astronomy was the subject (Adelaide Observer 
1848a, Adelaide Observer 1848b).

Astronomical themes had a particular resonance in Australia. Europeans had understood Australian identity as marked by astronomical events from early on in the colonial period. The strong symbolism of the Southern Cross in Australia arose through a perceived correspondence of the constellation with Ursa Major, and its consequent function as a social mnemonic for family and 'home' in the northern hemisphere (Bush 2017a, 48-70). The appearance of a number of bright 'Australian' comets first seen in the southern hemisphere was another nineteenth century way in which a sense of both locality and global imagination was marked through astronomical understanding (eg South Australian Register 1843). Astronomy was thus a powerful way through which a global imagination was developed for Australian colonists. An important popular science around the world, it could be deployed in Australia in a way that reflected both connection with Britishness and a distinctive identity.

These specific themes in Australia were seen alongside the persistent themes of astronomical lecturing described above. Religious lecturers, such as the Presbyterian "Apostle of the saddle" James Adam, used astronomy to harmonise science and religion (Bathurst Free Press 1861). The significance of the history of astronomy was given particular prominence by the lantern lectures of Richard Proctor in Australia (Bush 2017b); understanding the history of astronomy as the history of thought was also a theme of the Unitarian Archibald Camm (Sydney Morning Herald 1884). James Allen, Kesterton's lecturer, touched on most of these: religious implications, the history of astronomy and the exemplary nature of the science.

In any case, astronomical lantern sets were well used in Australia. Newspaper advertisements show that the "Popular lecture on Astronomy" set sold by Millikan and Lawley was particularly popular. ${ }^{7}$ Sets were manufactured in England, and marketed 
and sold by local businesses, in some cases by direct personal representatives. Henry Herbert Baker, grandson of instrument maker William Watson came to Australia for the 1888 exhibition and quickly opened a branch of family business selling, amongst other things, astronomical lantern slide sets (Wood, n.d.).

The stable mobile format of the astronomical slide set, with its standardised form and content, and accompanying reading, was especially relevant for the generalist lecturers in Australia, such as clergy and schoolteachers. Transparent orreries depended more on more specialist expertise of their users. Nonetheless, a number of such orreries were built and operated in colonial Australia, and even beyond that, their position in the field of popular astronomy lecturing was well appreciated. As in Britain, these devices shaped audience expectations of, and forms of demonstration for popular astronomy lectures in ways that would be picked up by the lanternists that followed.

\section{Transparent orreries were seen by Australian audiences}

The Eidouranion appears in colonial Australia in a number of ways. Although none reached the celebrated status of the famous devices of British stage astronomy, a number of transparent orreries were built and displayed in the colonies. Other antipodean performers invoked the names of famous to their own end; many of the audiences remembered them. Although travelling lecturers did not flourish in Australia until much later, and stage astronomy only ever had modest expressions, these are nevertheless revealing for understanding the influence of these forms of visualisation. I describe the most obvious cases below.

\section{John Cox's transparent orrery, 1833}

The first example for which there is good evidence is the device of John Cox, used in the Sydney Mechanics School of Arts. Cox was a cabinet maker who arrived in Sydney 
in November 1833. Within a year he was presenting a series of three astronomy lectures at the School of Arts, the last one before the Governor, Richard Bourke:

The Lecture tonight is Mr. Cox's second, on Astronomy. Mr. Cox has an assortment of very superior transparencies, illustrative of the different systems of Astronomy, of the various appearances of the heavenly bodies, in particular of the planetary movements , and of the disc and phases of the moon. He illustrates by this means too, several atmospherical phenomena; and his orrery, which is to be exhibited tonight, is not unworthy of a peep even from those who have witnessed the exhibitions of a London Lecturer. (Sydney Monitor 1834)

A notice advertising the lectures had been even more complimentary: Cox's "transparencies and apparatus" were "on a scale equal to those exhibited in London" (Sydney Gazette and New South Wales Advertiser 1834). These clear comparisons to the London stage astronomy lecturers is strongly indicative of an Eidouranion-type device along with transparency paintings. The evidence from the Sydney Mechanics' School of Arts archives is even more suggestive that Cox exhibited a transparent orrery. Minutes for the meetings of the committee of management immediately following Cox's offer to lecture record payments for calico, candles, and candlesticks. These are unusual items for the Sydney Mechanics' School of Arts ${ }^{8}$ but key components of a transparent orrery as described by the Magazine of Science.

The later history of Cox's device is unclear. In 1841 Cox returned to Britain and offered to sell his apparatus to the School of Arts Museum. This offer was accepted, and payment of his account recorded, but both subject to approval of the condition of the device (Sydney Mechanics' School of Arts 1833, see meetings Jun, Jul 1841). School of Arts stalwart Henry Hollinshed gave a lecture on Astronomy "Illustrated with a large transparent orrery" in 1850 (Sydney Morning Herald 1850), but there are no further details. Later in the 1850 s the Museum's contents were described as being in poor 
condition, and they were variously repaired or disposed of. The precise contents of the Museum appear not to have been properly catalogued at this time.

Phineas Moss 's transparent orrery, 1836

Another transparent orrery in Australia was made for the Bothwell Literary Society. Formed in 1834 in the Tasmanian town a few hours ride west of Hobart, this Society was one of the first such organisations to be established in Australia anywhere, and the first outside of the major cities. It appeared just a year after the Sydney School of Arts and Mechanics' Institute, and a good six years before Melbourne's. Only the Philosophical Society of Australasia, established in Sydney in 1821 predated it by more than a few years.

The local Presbyterian minister James Garrett lectured on astronomy at Bothwell, in both 1836 and 1839. These lectures included a series of transparent paintings including original imagery such as a chart of circumpolar stars as seen from Tasmania, as well as copies of more familiar diagrams such as the orbits of the planets in the solar system. These transparency paintings were done by Phineas Moss, then police clerk at Bothwell. Moss was also the Literary Society's librarian and clearly an accomplished painter. He produced nearly three hundred paintings and diagrams for the society, including a much-admired transparency painting of Mt Etna (Hobart Town Courier 1839a, Hobart Town Courier 1839b). Before coming to Tasmania in 1835 Moss had been one of the founders of the Bath Mechanics' Institute; later, when he moved to Hobart, Moss would act as Honorary Secretary of the Hobart Mechanics' Institution, Honorary Secretary of the Hobart Synagogue, and was a member of The Royal Society of Van Diemen's Land. He combined many of his interests in his 1859 paper to the Royal Society on the 'Science of Astronomy amongst the Ancient Jews' (Moss 1859). 
The reports of the lectures, however, make it clear that these were not simple transparency paintings: they were mechanical devices that produced moving images The 1836 lecture

was illustrated by a splendid transparent Planetarium, with machinery shewing the various Eclipses and a transit of Venus over the Sun's disk, (the invention of Mr. Moss) this exhibition was superior to anything of the kind before seen in the island.

The eclipses and transits would likely have been visualised with a large sliding mechanism. However the 'transparent Planetarium' must have involved rotating planetary images, broadly similar in plan to the Magazine of Science device. The reference to the 'superior' quality of the exhibition can no doubt be taken lightly, but does refer to two things: the previous visualisations seen in Tasmania, particularly the lectures by schoolteacher Ronald Giblin between 1827 and 1830, which had included a pair of globes, transparent diagrams and a "planetarium invented by himself" which had made at least one reviewer think of "Old England and Walker's Orrery" (Colonial Times 1827, Hobart Town Gazette 1827, Hobart Town Courier 1829, Colonial Times 1830). The devices of both Moss and Giblin show that audiences were comparing these displays to their memories of the London stage astronomers, and in Moss's case, at least, a sophisticated mechanism was built.

\section{John Meredith’s 'Dioastrodoxon', 1837}

A slightly more ambiguous case is the 'Dioastrodoxon' advertised by pioneer of Australian theatre John Meredith in Hobart in 1837. Meredith, with the theatrical background that Huang (2016) draws attention to, was very much presenting astronomy for commercial interests, and drew on the names of the London stage astronomers to do so. For good measure, Meredith used the name of both the Walkers' Eidouranion and 


\section{Lloyd's Dioastrodoxon.}

The nature of what Meredith presented is not entirely clear. His advertisement is unequivocal: a "working orrery, made by himself, expressly for the occasion, after the manner of Walker's celebrated Eidouranion" (Colonial Times 1837a). Another section of the paper reports the claim

From a person who has been permitted to witness the machinery prepared for the illustration of the lectures, we learn that it is exceedingly well contrived, and if the lecturer is as perfect as his orrery, the inhabitants of Hobart Town will have the enjoyment of a delightful exhibition. (Colonial Times 1837b)

While these extracts appear unequivocal, there appear to be no printed reports of the lecture itself, or its apparatus.

While Cox and Moss had predominantly educational motives for the construction of their devices, Meredith had more commercial interests. Although one of the colonial audiences' favourite actors, Meredith had a history of disputes with his fellow performers, including a notorious incident in Sydney in which, as stage manager, he threw from the stage two actors who had attempted to protest against their dismissal from the company (Flaherty 2016). By 1837 Meredith was managing the only theatre in Hobart, but when a rival theatre opened — and poached most of his actors-Meredith soon found himself in financial difficulties. His several attempts to re-open a theatre foundered, and the astronomical lecture was presented in an attempt to remedy his situation.

Soon afterwards Meredith returned to Sydney, where he repeated his astronomy lectures between 1841 and 1844 . The first of these was performed as part of a benefit for Mr Belmore, a theatrical machinist who had been associated with Meredith in both Sydney and Hobart (M.-R. Jones 2007). The advertisement claims that: 
Mr Belmore, having lately received from England per Canton, complete machinery for a Grand Orrery, on a most extensive scale, will have the honour of exhibiting, for the first time in this colony, several Diagrams, as here under set forth (Australian 1841)

This provides evidence for the existence of a true Eidouranion-like machine in operation, but also raises questions. Certainly Belmore would have the right kind of skills to construct such a device. On the other hand, if one was able to be constructed afresh in Hobart, why did it need to be imported in Sydney? One possibility is that word of mouth had led to a poor perception of the Hobart performance. On the other hand, Meredith and Belmore may have simply been seeking to boost the reputation of their apparatus. Again, there are no reports by third parties of the performance itself. The "several diagrams" described by the advertisement read like the synopsis of a standard commercial astronomical lantern slide similar to W. \& S. Jones's, although without further description it is difficult to distinguish between a set of projected images and a series of transparency paintings of the same. Later notices for lectures in 1842 and 1844 generally reprise the Hobart advertisement. Meredith's 'Dioastrodoxon' is thus a likely, but not definitive example of a transparent orrery exhibited in Australia. In any case, Meredith's advertising shows the strength of the reputation of the stage astronomers.

\section{Laurence Hynes Halloran's solicitation, 1830}

Some other examples showing the influence of the Eidouranion on popular consciousness in the Australian colonies clearly do not involve devices at all. The first time that the name 'Eidouranion' was prominently used in public in Australia was in 1830, by failed schoolteacher Laurence Hynes Halloran. Halloran was a colourful figure: jailed at 18 for stabbing a shipmate, insolvent at 31 after a failed school and ruined again at 45 after having published defamatory verse in Cape Town, Halloran had 
been transported to Australia, age 53, for forging credentials as a curate. He was granted a ticket-of-leave by Governor Macquarie and briefly found success as a schoolmaster before further legal actions landed upon him. "From year to year he was forced to move his school to escape his creditors, and a series of libel suits and several periods of imprisonment for debt reduced him to beggary" (Austin 1966). By 1830, Halloran had opened and closed another school, founded a newspaper that folded — under the weight of defamation actions - and been appointed Coroner, but quickly dismissed, again, for potential libels. He died shortly afterwards, aged 66.

Halloran's invocation of the Eidouranion was an attempt to stave off bankruptcy. He offered to the public a lecture series on the British Constitution. However, should this be successful, he proposed for a second series "to procure from England, with the least possible delay, an Eidouranion or Orrery for the purpose of introducing Lectures on Astronomy, and of encouraging among the youth of the Colony, a taste for that sublime science" (Halloran 1830). The promise of spectacular astronomical visualisation appeared as a financial gambit by a down-on-their-luck member of the educated classes for the first — but not the last—-time in Australian history. Although unsuccessful, Halloran's appeal shows that the Eidouranion was a well known device for middle-class audiences in the colonies at this time.

Sydney Royal Polytechnic, 1854

A less flamboyant, but perhaps more revealing example, is James Smith Norrie, analytical chemist and proprietor of the Sydney Royal Polytechnic. Like Halloran, Norrie invoked the reputation of the Eidouranion for financial gain. Unlike Halloran, however, Norrie was able to produce a display. However it was not a transparent orrery that Norrie exhibited at his Polytechnic, but rather a set of astronomical lantern slides. 
Norrie opened the commercial exhibition invoking the name of the famous London Royal Polytechnic in Sydney in 1854. He had arrived in in New South Wales in 1840 and four years later was the first government chemist appointed. This position was on a fee-for-service basis, and Norrie maintained business interests outside of his government work. The Polytechnic was one of his major enterprises, and visualisation was a key component. Both Norrie's advertising, and most reports of the Royal Polytechnic focus on the range of dissolving views and chromatropes displayed.

One visualisation that Norrie emphasised was the "immense orrery" (Sydney Morning Herald 1854, Empire 1854b). Originally announced with the opening of the Royal Polytechnic, in March 1854, it was not until eight weeks later that the lectures in astronomy commenced on the $3^{\text {rd }}$ May. Like Halloran and Meredith before him, Norrie associated his device with one of the London stage astronomers, in this case Charles Henry Adams, the longstanding British astronomical lecturer who was described by one periodical as "the only orthodox interpreter of astronomy" (Era 1856). A review of Norrie's lecture described it as "lucid and comprehensive" (Empire 1854a) and made its physical form clear: a display on canvas. Norrie was presenting an orrery slide, by that time readily available, projected by a lantern.

The 1850s mark the end of the stage astronomy, in Britain and elsewhere. In the second half of the nineteenth century lantern slides became the dominant form of public visualisation of astronomy. Platform lecturers of astronomy, like the Proctors, would go on to shift performances practices further. At this point the contribution to visualisation to forms such as printed wall charts and mechanical models needs to be remembered, but the older tradition of stage astronomers contributed little more.

\section{The Eidouranion had an influence on Australian lanternists}

The devices of stage astronomy constructed in Australia were modest, but their presence 
is revealing of the influence of the tradition beyond its exemplary performers. This influence is important for understanding the early development of astronomical lanternism, and its optical forms of demonstration. There are two aspects of this that I have emphasised, relating to mobility and stability.

\section{Astronomical lecturing involved stable mobile technologies}

The astronomical lantern slide set as an 'immutable mobile' had power because it could travel efficiently, yet the relations between the skills of the lanternist, the quality of the reading and the expectations of the audience remained stable, over an extended period of time. The devices of stage astronomy were not quite as mobile, yet the tradition was, extending at least as far as the Australian colonies in the nineteenth century. The use of and references to transparent orreries and similar devices in antipodean colonies is illustrative of the extent of the practice, for middle class audiences at least.

Technological innovation was certainly a feature of the astronomical lecturing tradition in all of its guises. The advertisements of stage astronomers, like Mr Franklin's in Figure 8 b), often referred to newly constructed apparatus; entrepreneurs like Meredith and Kesterton emphasised that their devices were new or that their lanterns were of superior quality. Nonetheless, the traditions overall remained solid. Audience expectations of a given performance, such as expressed by writers like Edgeworth, were clear. This was, in large part, due to the stable forms of optical demonstration developed by the stage astronomy tradition.

\section{The aesthetics of astronomical lecturing were persistent}

Alongside the technological forms, the cultural themes of popular astronomy were persistent. The astronomical sublime, the relevance of astronomy to religiosity and the antiquity of the science were long-lived aspects of interpretation. Many of these themes 
were expressed in popular astronomy before the eighteenth century; some of them lasted into the twentieth and twenty-first centuries.

These persistent themes were expressed in a new visual way by astronomical lecturers of the late eighteenth and early nineteenth centuries. The adoption by lantern slide manufacturers and lanternists of these optical forms of demonstration shows how technological forms can overlap in practice. This aspect has been studied recently in the transition from lantern culture to cinema, but its presence in early lanternism has been less discussed. The transfer of visual techniques is interesting at both ends of the magic lantern period.

\section{Conclusion}

Stage astronomers in nineteenth century Australia built devices to display their cultural heritage, and invoked the name of famous London showmen to enhance their reputations. Their motivations spanned the full range from the 'commercial' to the 'sublime'; their performances drew on practices from many places. In doing so, they ushered in the visual techniques that would form the repertoire of astronomical lanternists throughout the nineteenth century. 


\section{References}

Adelaide Observer. 1848a. "Local Intelligence," January 8, 1848.

. 1848b. "Local Intelligence," January 22, 1848.

Age. 1879. "Science in State Schools," August 9, 1879.

An Explanatory Catalogue of the Cosmorama. 1807. London, UK: Harper \& Co.

Argus. 1884. "Popular Astronomy," June 19, 1884.

Austin, Albert Gordon. 1966. "Halloran, Laurence Hynes (1765-1831).” Australian

Dictionary of Biography. National Centre of Biography, Australian National

University. http://adb.anu.edu.au/biography/halloran-laurence-hynes-

2149/text2741,.

Australian. 1841. "Advertising. Royal Victoria Theatre. For the Benefit of Mr Belmore

(Machinist)," December 23, 1841.

Barnaby, Alice. 2009. "Light Touches : Cultural Practices of Illumination, London

1780-1840.” PhD, Exeter, UK: University of Exeter.

Bathurst Free Press. 1861. "Carcoar," August 14, 1861.

Bendigo Advertiser. 1906. "Mr Frank T. Bullen," March 28, 1906.

Bigg, Charlotte, and Kurt Vanhoutte. 2017. "Spectacular Astronomy." Early Popular

Visual Culture 15 (2): 115-24. https://doi.org/10.1080/17460654.2017.1319037.

Bijker, Wiebe E. 1995. Of Bicycles, Bakelites, and Bulbs: Toward a Theory of

Sociotechnical Change. Cambridge, Mass.: MIT Press.

Bird, Richard. 2005. "Enlightenment and Entertainment: The Magic Lantern in Late

18th- and Early 19th-Century Madrid." In Realms of Light: Uses and

Perceptions of the Magic Lantern from the 17th to the 21st Century: An

Illustrated Collection of Essays by 27 Authors from Six Countries, edited by

Mervyn Heard and I. Van Dooren, 86-91. Magic Lantern Society.

https://books.google.com.au/books?id=pO5TAAAAMAAJ.

Blunt, Charles F. 1816. "Advertisement. C. Blunt Optician and Mathematical

Instrument Maker." Quarterly Review, 1816.

. 1840. The Beauty of the Heavens: A Pictorial Display of the Astronomical

Phenomena of the Universe. London: Tilt and Bogue.

Bush, Martin. 2017a. "A History of Popular Astronomy in Australia in the Era of the Lantern Slide: 1825-1910." PhD, Melbourne, Victoria: Swinburne University of Technology. http://hdl.handle.net/1959.3/440779.

2017b. "The Proctor-Parkes Incident: Politics, Protestants and Popular

Astronomy in Australia in 1880." Historical Records of Australian Science 28

(1): 26-36.

2018. "1891: The Collins-Hosking Debate, Christchurch.” Public

Understanding of Science, May, 963662518771400.

https://doi.org/10.1177/0963662518771400.

Callaway, A. 2000. Visual Ephemera: Theatrical Art in Nineteenth-Century Australia.

UNSW Press. https://books.google.com.au/books?id=kjidEHGfTCQC.

Clarke, Edward M. 1842. List of Prices of Mathematical Philosophical, Optical, and

Chemical Instruments and Apparatus Manufactured by Edward M. Clarke,

Philosophical Instrument Maker. Taylor and Walton.

https://books.google.com.au/books?id=0bQ-AAAAcAAJ.

Clegg, John. 1797. A Concise Description of Dicas's Portable Eidouranion, or Astronomical Lucernal. Liverpool: Swarbreck, printer.

Colonial Times. 1827. "Mechanic's Institution," September 7, 1827. 1830. "Mechanics' Institution," March 12, 1830.

. 1837a. "Dioastrodoxon or the Heavens Displayed," August 29, 1837. 
1837b. "Domestic Intelligence," August 29, 1837.

Courcy, Elisa de. 2018. "Magic Lantern Culture as a Challenge to Area Studies:

Mobility, Recombination and Experimentation." In Papers from the $2018 \mathrm{PKU}$ ANU-Tokyo Winter Institute, 81-88. Tokyo, Japan: University of Tokyo Center for Philosophy Press.

Edgeworth, Maria. 1825. Frank. A Sequel to Frank, in Early Lessons. 2nd ed. Vol. 2. 3 vols. London, UK: R. Hunter.

Empire. 1854a. "The Royal Polytechnic," June 2, 1854.

. 1854b. "Advertising. Royal Polytechnic," June 15, 1854.

Era. 1856. "(No Title)," May 23, 1856.

Flaherty, Kate. 2016. "'Damn Him and the Spikes': Richard III, Riot, and the Formation of an Australian Colonial Theatre Public." Cogent Arts \& Humanities 3 (1): 1237141 .

Flatters \& Garnett. 1924. Lantern Slides Illustrating Zoology, Botany, Geology, Astronomy, Textiles \&c. 4th ed. Manchester, UK: Flatters \& Garnett.

Francis, George William. 1840. "Astronomical Illustrations." The Magazine of Science and School of Arts, April 4, 1840.

Golinski, Jan. 2017. "Sublime Astronomy: The Eidouranion of Adam Walker and His Sons." Huntington Library Quarterly 80 (1): 135-57.

Goodacre, Robert. 1821. "Robert Goodacre from Bradford to Robert Goodacre Jnr., Standard Hill, 1821 September 20." Bradford. History of the family of Goodacre. Bromley House Library.

Halloran, Laurence Hynes. 1830. "Public Lectures.” Australian, July 30, 1830.

Hartrick, Elizabeth. 2017. The Magic Lantern in Colonial Australia \& New Zealand. Accessed from https://nla.gov.au/nla.cat-vn7376509. North Melbourne, Vic: Australian Scholarly Publishing.

Hawthorne, Julian. 1873. Bressant. New York, NY: D. Appleton.

Heard, Mervyn. 2005. "A Prurient Look at the Magic Lantern.” Early Popular Visual Culture 3 (2): 179-95. https://doi.org/10.1080/17460650500198055.

Hobart Town Courier. 1829. "Mechanics' Institution," November 28, 1829. 1839a. "Bothwell Literary Society," August 9, 1839. 1839b. "Bothwell," November 8, 1839.

Hobart Town Gazette. 1827. "Hobart-Town. Saturday September 8, 1827," September 8, 1827.

Huang, Hsiang-Fu. 2015. "Commercial and Sublime: Popular Astronomy Lectures in Nineteenth Century Britain.” PhD, University College London.

—. 2016. "When Urania Meets Terpsichore: A Theatrical Turn for Astronomy Lectures in Early Nineteenth-Century Britain." History of Science 54 (1): 4570.

Ipswich Journal. 1838. “Colchester January 19. Died,” January 20, 1838.

Jones, Maree-Rose. 2007. "Musical Activities at the Royal Victoria Theatre, Hobart, van Diemen's Land.” Papers and Proceedings: Tasmanian Historical Research Association 54 (3): 144-53.

Jones, W. and S. 1797. A Catalogue of Optical, Mathematical, and Philosophical Instruments, Made and Sold by W. and S. Jones, No. 135, Next Furnival's-Inn, Holborn, London.

King, H.C., and J.R. Millburn. 1978. Geared to the Stars: The Evolution of Planetariums, Orreries, and Astronomical Clocks. University of Toronto Press. https://books.google.com.au/books?id=0gJAAQAAIAAJ. 
Latour, Bruno. 1990. "Drawing Things Together." In Representation in Scientific Practice, edited by Michael Lynch and Steve Woolgar, 19-68. Cambridge, Mass.: MIT Press.

Launceston Examiner. 1844. "Mechanics' Institute," September 21, 1844.

Lloyd, Robert Evans. 1810. An Epitome of Astronomy, Its Origin and Progress. Nottingham.

Maitland Mercury and Hunter River General Advertiser. 1846. "Tea Party and Lecture," April 15, 1846.

Martin, Benjamin, 1705-1782. 1740. A New and Compendious System of Optics. London: Printed for J. Hodges.

Moss, Phineas. 1859. "On the Science of Astronomy amongst the Ancient Jews." Papers \& Proceedings of the Royal Society of Tasmania 3: 221-227.

South Australian Advertiser. 1861. "Lecture at the Institute," December 28, 1861.

South Australian Register. 1843. "The Australian Comet," April 12, 1843.

Sydney Gazette and New South Wales Advertiser. 1834. "Sydney Mechanics' School of Arts.," October 18, 1834.

Sydney Mechanics' School of Arts. 1833. "Minutes of the Sydney Mechanics' School of Arts 1833-1900 and of the Working Men's College 1873-1883." Sydney, NSW. CY2153. Mitchell Library.

Sydney Monitor. 1834. "Sydney Mechanics' School of Arts," November 15, 1834.

Sydney Morning Herald. 1850. “Advertising. Mechanics' School of Arts," September 24, 1850 . 1854. "Advertising. Royal Polytechnic Exhibition," February 20, 1854. 1884. "News of the Day," September 11, 1884.

Telescope, Tom. 1761. The Newtonian System of Philosophy Adapted to the Capacities of Young Gentlemen and Ladies : ... Being the Substance of Six Lectures Read to the Lilliputian Society, by Tom Telescope, A.M. and Collected and Methodized ... by ... Mr. Newbery. London: J. Newbery.

The Post Office London Directory. 1843. Kelly's Directories Limited. https://books.google.com.au/books?id=lw87AQAAMAAJ.

Walker, William. 1798. An Epitome of Astronomy, with the New Discoveries: Including an Account of the Eidouranion, or Transparent Orrery. Thirteenth. Bury: P. Gedge.

Wellbeloved, Horace. 1826. London Lions for Country Cousins ... A Display of Metropolitan Improvements, the New Streets, New Bridges, New Churches, Etc. ... Second Edition. London.

Wood, Harley. n.d. "Baker, Henry Herbert (1867-1940)." Australian Dictionary of Biography. Canberra: National Centre of Biography, Australian National University. https://adb.anu.edu.au/biography/baker-henry-herbert-5105. 
(The Post Office London Directory 1843)

(Hartrick 2017)

(Launceston Examiner 1844, Maitland Mercury and Hunter River General Advertiser

1846, South Australian Advertiser 1861, Age 1879, Argus 1884)

${ }^{1}$ I use this term throughout to refer to astronomical lecturing that involved physical apparatus of display, despite the fact that not all such performances were theatrical or commercial.

${ }^{2}$ Horace Wellbeloved (1826) in London Lions attributes astronomical slides to Charles Blunt. However Blunt did not enter into partnership with his father, optician Thomas Blunt until 1801, and did not operate under his own name until 1811, so Wellbeloved would seem to be incorrect about this detail. The curious note that "The relation in which the editor of this work stands with respect to the ingenious inventor of these paintings, will hardly allow him to advert to the rude imitators of his paintings" raises the prospect that Wellbeloved was a psudeonym for Blunt himself, or one of his associates.

${ }^{3}$ Mary took over this business from her father in this year, and operated it under her own name until around 1807 at which time she formed a partnership with scale-maker George Arstall, with whom she had several children after 1810. In the 1807 Gore's Directory for Liverpool Dicas and Arstall appear jointly as instrument makers; in the 1810 directory only Arstall's name appears. On the other hand the printer of the pamphlet advertising the Lucernal, Thomas Swarbreck does not appear before 1807.

${ }^{4}$ The Keevil brothers appear to have started to use their large rackwork slide, described by Golinski (2017) around 1839. Rackwork sets are advertised by Carpenter and Westley from the early 1840s. See eg their advertisement in the Post Office London Directory (1843, 1626).

${ }^{5}$ See Hartrick (2017) for a comprehensive account of the magic lantern in Australia.

${ }^{6}$ A few commercial lanternists appeared in the Australian colonies, like Joseph Newland and Henry Kesterton but were generally unsuccessful. See eg de Courcy (2018).

${ }^{7}$ Newspaper advertisements give synopses of lectures that match the slide set almost exactly. See the lectures of eg Charles Price, John Jennings Smith, James Martin, Hugh Wylie and 
Frederic Race Godfrey (Launceston Examiner 1844, 4; Maitland Mercury 1846, 2; South Australian Advertiser 1861, 3; Age 1879, 1; Argus 1884, 6).

${ }^{8}$ No other accounts for a period of at least three years around these meetings record such payments. At this stage the School of Arts did not have a permanent home, but was meeting in a house on Church Hill in the Rocks. There are separate accounts for lighting here, so candles are out of place in this context. 